\title{
Minimize Noise Dose Exposure by Karnaugh Map Technique for a Small Scale Manufacturing Industry in West Bengal of India
}

\author{
Pijush Kanti Bhattacharjee, Member, IACSIT, Tirtharaj Sen, Debamalya Banerjee, Bijon Sarkar
}

\begin{abstract}
Noise is one of the most found physical contaminants in the manufacturing Industry. Professional deafness or even permanent hearing loss may produce due to most negative effect caused by noise exposure. It also produce ill effects on people's health, since basic activities such as sleeping, resting, studying and communicating etc. are highly affected. It endures high environmental pollution. We have collected different noise related parameters like $L_{\text {eq }}$ (Equivalent sound level), $L_{a v}$ (Average sound level), $L_{A E}$ (Sound exposure level) and TWA (Time Weighted Average level) from different machines used in an industry, especially power press machine, grinding machine etc. We propose a noise exposure minimizing technique with the help of Karnaugh map which is generally used in Boolean algebra simplification. By implementing Karnaugh map technique, different noise exposure parameters are minimized, and maximum sound exposure sources are identified.
\end{abstract}

Index Terms- Precision dosimeter, Small scale Industry, Noise exposure, Effect of noise, Karnaugh map.

\section{INTRODUCTION}

Unlike other contaminant agents, the effect of noise may be instantaneously unnoticed and its accumulation can lead a social, psychic and physical deterioration. The loss of hearing is the effect of over-exposure in noisy environment. It is one of the causes in environmental pollution.

Every day in West Bengal, thousands of workers, especially in manufacturing units, are exposed to noise and consequently they are affected risks and deterioration of health in their workplace. One, out of ten workers in West Bengal must raise his voice to be heard for more than one third period of the working day and 5-7\% of them suffer from noise related hearing problem [3]-[13].

Manuscript received March 24, 2011.

Pijush Kanti Bhattacharjee is an Assistant Professor in the Department of Electronics and Telecommunication Engineering in Assam University (A Central University), Silchar, Pin 788011, Assam, India.

(phone: +91-33-25954148, email: pijushbhatta_6@hotmail.com).

Tirtharaj Sen is an Assistant Professor in the Department of Electrical Engineering, Asansol Engineering College, Kanyapur, Vivekananda Sarani,

Asansol, Burdwan-713305, India.

(Phone: +91-9432851324, email: tirtha.bitm@gmail.com)

Dr. Debamalya Banerjee, Ph.D(Engg.) is currently a Reader in the Department of Production Engg., Jadavpur University.

(Phone: +91-9432283650, email: debamalya_banerjee@yahoo.co.uk)

Dr. Bijon Sarkar is currently a Professor in the Department of Production

Engineering, Jadavpur University, Kolkata, India.

(Phone: +91-9432283650, email: bijon_sarkar@email.com)
For the study and health of workers, noise exposure can cause several risks. The risk of accidents in the workplace is increased due to noise flowing beyond the limit. The speech and alarm sound can mask both due to noise exposure. Different physical problems like voice problems, nodules, abnormalities in the vocal cord, loss of voice, hearing problem, migraine etc. are suffered by our workers. It is more dominant when the workers are subjected to communicate with in noisy environment with more than 90 dBA levels.

As it is involved with the market interest of a company as well as employee's health issue, excess noise removal in the work place is not just a legal responsibility of the organization, but it is also a burning crisis to all.

This work has studied in the manufacturing unit of a sheet metal industry which creates a very noisy zone in the factory premises. The same results with little variations are obtained in all other sectors of the small scale industries in West Bengal state of India. It causes serious environmental pollution. Hence it effects country's development. Previously noise levels were studied by many researchers like Nelson et al. (1999), M.A Martin et al. (2006), Marcos D. Fernandez et al. (2009) and Ktarina Paunovic et al. (2009). After calculating different noise exposure parameters by Noise Dose meter, we minimize these noise parameters or variables by adopting Karnaugh map technique which is generally used for Boolean algebra simplification purpose.

This innovation of applying Karnaugh map technique in minimizing noise exposure is the first time use in environmental pollution area. The minimized form of noise parameters assigns a new simplified noise solution for noise exposure measurement.

\section{METHODOLOGY OF THE STUDY}

We are studying the characteristics of noise dose from different machines, like power press and grinding machine in a small scale industry in Kolkata city, West Bengal, India.

The factory unit is a manufacturer of emergency car brake in which different sheet metal components are assembled.

The noise standards are generally set on the basis of World Health Organization (WHO) stipulations [11], [12]. WHO has stipulated $65 \mathrm{~dB}$ permissible noises from an industrial area during both day and night. In commercial area it is 60 $\mathrm{dB}$ whereas $55 \mathrm{~dB}$ and $45 \mathrm{~dB}$ is prescribed for commercial, residential and silence zones respectively.

The following measures have to be applied in the work place that overpasses a daily equivalent level of $70 \mathrm{~dB}$ and a peak level of $140 \mathrm{~dB}$. 
1) The workers are to give personal hearing devices that demand them.

2) Once in every three years, the workers are subjected to initial medical checkup or hearing.

3) Each worker is provided with a proper information for

- Use of personal hearing system.

- $\quad$ Regular medical hearing checkup.

- Potential risks for hearing and assessment for Noise exposure.

\section{A. Instrument Used}

Type 4444, Noise Dose Meter has been used for recording assessment and noise level associated with the workers in that small scale industry. It is a light weight instrument. There are seven build in setups, which include, ISO 90A, ISO 85A, DOD, MSHA, ACGIH, (USA standards) and obviously a very important unit is OSHA, which corresponds to most widely used standards today. The meter has a capability to store the data to memory, the sound level setups are specified in which SLM gives on screen result and METER can store data to memory.

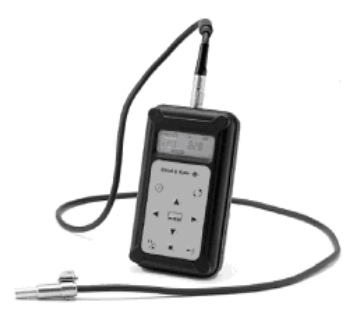

Fig.1.Noise Dose Meter 4444 used for this study

\section{B. Method of measurement}

Measurements are done in presence and also absence of noise exposure from machines to the effected workers by placing the microphone in his collar (the microphone will be placed preferably in front of his ear, approximately at a distance of $10 \mathrm{~cm}$ ). For this study, measurements are taken according to ISO 1999: 1990 "Guidelines for the measurement and assessment of exposure to noise in a working environment" [11], [12].

For this study, an integrative and averaging Bru“ el \& Kjær, made Noise Dose Meter type 4444 has been used. The measurements are made using the dosimeter computing some common indexes like, $\mathrm{L}_{\mathrm{eq}}, \mathrm{L}_{\mathrm{av}}, \mathrm{L}_{\mathrm{AE}}$ and TWA.

Where, $\mathrm{L}_{\mathrm{eq}}=$ Equivalent sound level,

$\mathrm{L}_{\mathrm{av}}=$ Average sound level,

$\mathrm{L}_{\mathrm{AE}}=$ Sound exposure level,

TWA = Time Weighted Average level.

All measurements are taken in OSHA which is an international standard.

The industry plant is a manufacturer of hydraulic gear for car and has a press shop where seven 100 Ton, one 150 Ton, one 25 Ton Power press machines and one medium size Grinding machine are working. The plant is running in two shifts, morning and evening each for 8 hours. Leisure period is 30 minutes for both shifts. The registered parameters with the dosimeter are:

- Duration of measurement ( Time in sec),

- Maximum and minimum threshold level Losha1 and $\mathrm{L}_{\mathrm{OSHA} 2}$ for individual machine,
- Equivalent continuous A-weighted sound pressure level, registered along the whole measurement $\left(\mathrm{L}_{\mathrm{eq}}\right.$, $\mathrm{T}$ in dBA),

- Threshold level is $80 \mathrm{~dB}$ and criteria level is $90 \mathrm{~dB}$,

- Upper and lower threshold value for individual machine,

- 8 hour percentage projected dose,

- Exchange rate $\mathrm{Q}=5$,

- $\quad$ Exceedance times from sound pressure level (SPL).

\section{RESULTS AND DISCUSSION}

From noise related parameters or variables like $\mathrm{L}_{\mathrm{eq}}, \mathrm{L}_{\mathrm{av}}$, $\mathrm{L}_{\mathrm{AE}}$ and TWA, we take average threshold level for each parameter and make a truth table for the same. If any one of the variables is greater than the threshold value, i.e., noise is exposed more than normal limit, then the value is taken as one (1), and if less than the threshold value, i.e., noise is tolerable, then it is taken as zero $(0)$.

Here we are selecting only four (4) variables (parameters) out of ten noise sources (Machines). For 100 Ton Power press machines, average value is taken. Apart from that, one 150 Ton Power press machine, one 25 Ton Power press machine and one Grinding machine are selected.Table-1 shows details of all machine parameters.

TABLE-I: NOISE PARAMETERS (VARIABLES) MEASURE FROM DIFFERENT

\begin{tabular}{|c|c|c|c|c|}
\hline $\begin{array}{c}\text { Machine Type/ } \\
\text { Sound level }\end{array}$ & $\begin{array}{c}\mathrm{L}_{\mathrm{eq}} \\
(\mathrm{dBA})\end{array}$ & $\begin{array}{c}\mathrm{L}_{\mathrm{av}} \\
(\mathrm{dBA})\end{array}$ & $\begin{array}{c}\mathrm{L}_{\mathrm{AE}} \\
(\mathrm{dBA})\end{array}$ & $\begin{array}{c}\text { TWA } \\
(\mathrm{dBA})\end{array}$ \\
\hline $\begin{array}{c}\text { Power press }-1 \\
(100 \mathrm{~T})\end{array}$ & 98.2 & 128.0 & 98.0 & 73.4 \\
\hline $\begin{array}{c}\text { Power press -2 } \\
(100 \mathrm{~T})\end{array}$ & 99.9 & 120.6 & 97.6 & 57.9 \\
\hline $\begin{array}{c}\text { Power press -3 } \\
(100 \mathrm{~T})\end{array}$ & 111.5 & 126.5 & 108.5 & 59.4 \\
\hline $\begin{array}{c}\text { Power press -4 } \\
(100 \mathrm{~T})\end{array}$ & 100.6 & 128.7 & 100.3 & 72.9 \\
\hline $\begin{array}{c}\text { Power press -5 } \\
(100 \mathrm{~T})\end{array}$ & 98.0 & 117.5 & 97.2 & 55.5 \\
\hline $\begin{array}{c}\text { Power press -6 } \\
(100 \mathrm{~T})\end{array}$ & 96.2 & 125.2 & 95.9 & 70.0 \\
\hline $\begin{array}{c}\text { Power press -7 } \\
(100 \mathrm{~T})\end{array}$ & 98.0 & 127.0 & 97.7 & 71.9 \\
\hline $\begin{array}{c}\text { Power press-1 } \\
(150 \mathrm{~T})\end{array}$ & 97.6 & 127.3 & 97.2 & 72.4 \\
\hline $\begin{array}{c}\text { Power press-1 } \\
(25 T)\end{array}$ & 98.5 & 128.1 & 98.5 & 73.5 \\
\hline $\begin{array}{c}\text { Grinding } \\
\text { Machine-1 }\end{array}$ & 91.6 & 117.1 & 91.5 & 59.8 \\
\hline
\end{tabular}

The above Table- 1 is transferred to Table-2 by reducing seven 100T Power press machines to a single 100T Power press machine, average value of all $100 \mathrm{~T}$ machines are taken.

Now, upper threshold level for all noise parameters which are available from Dosimeter for individual machine are taken in Table-3, we are ignoring lower threshold value, although it is available in Dosimeter. Since, upper threshold value assures that beyond this value, noise is more dominant factor and creating environmental pollution. 
TABLE-II: SIMPLIFIED STRUCTURE OF NOISE SOURCES WITH NOISE PARAMETERS.

\begin{tabular}{|c|c|c|c|c|}
\hline $\begin{array}{c}\text { Machine Type/ } \\
\text { Sound level }\end{array}$ & $\begin{array}{c}\mathrm{L}_{\mathrm{eq}} \\
(\mathrm{dBA})\end{array}$ & $\begin{array}{c}\mathrm{L}_{\mathrm{av}} \\
(\mathrm{dBA})\end{array}$ & $\begin{array}{c}\mathrm{L}_{\mathrm{AE}} \\
(\mathrm{dBA})\end{array}$ & $\begin{array}{c}\text { TWA } \\
(\mathrm{dBA})\end{array}$ \\
\hline $\begin{array}{c}\text { Average value for } \\
\text { seven 100 Ton } \\
\text { Power Press }\end{array}$ & 100.34 & 124.78 & 99.31 & 65.85 \\
\hline $\begin{array}{c}\text { Power press -1 } \\
(150 \mathrm{~T})\end{array}$ & 97.6 & 127.3 & 97.2 & 72.4 \\
\hline $\begin{array}{c}\text { Power press -1 } \\
(25 \mathrm{~T})\end{array}$ & 98.5 & 128.1 & 98.5 & 73.5 \\
\hline $\begin{array}{c}\text { Grinding } \\
\text { Machine-1 }\end{array}$ & 91.6 & 117.1 & 91.5 & 59.8 \\
\hline
\end{tabular}

TABLE-III: UPPER THRESHOLD VALUE FOR ALL NOISE PARAMETERS

Average threshold value is $97.12 \mathrm{dBA}$.

\begin{tabular}{|l|l|}
\hline Power press-1 (100T) & $97.7 \mathrm{dBA}$ \\
\hline Power press-2 (100T) & $95.9 \mathrm{dBA}$ \\
\hline Power press-3 (100T) & $96.6 \mathrm{dBA}$ \\
\hline Power press-4 (100T) & $100.3 \mathrm{dBA}$ \\
\hline Power press-5 (100T) & $100.5 \mathrm{dBA}$ \\
\hline Power press-6 (100T) & $97.3 \mathrm{dBA}$ \\
\hline Power press-7 (100T) & $90.3 \mathrm{dBA}$ \\
\hline Power press-1 (150T) & $97.1 \mathrm{dBA}$ \\
\hline Power press-1 (25T) & $98.5 \mathrm{dBA}$ \\
\hline Grinding Machine-1 & $97.1 \mathrm{dBA}$ \\
\hline
\end{tabular}

On the basis of the above threshold value, the truth table is constructed as shown in Table-IV.

TABLE-IV: TRUTH TABLE FOR NOISE PARAMETERS VERSES NOISE SOURCE.

\begin{tabular}{|c|c|c|c|c|}
\hline $\begin{array}{c}\text { Machine Type/ Sound } \\
\text { level }\end{array}$ & $\begin{array}{c}\mathrm{L}_{\mathrm{eq}} \\
(\mathrm{dBA})\end{array}$ & $\begin{array}{c}\mathrm{L}_{\mathrm{av}} \\
(\mathrm{dBA})\end{array}$ & $\begin{array}{c}\mathrm{L}_{\mathrm{AE}} \\
(\mathrm{dBA})\end{array}$ & $\begin{array}{c}\text { TWA } \\
(\mathrm{dBA})\end{array}$ \\
\hline $\begin{array}{c}\text { Average value for seven } \\
\text { 100 Ton Power Press }\end{array}$ & 1 & 1 & 1 & 0 \\
\hline Power press-1 (150T) & 1 & 1 & 1 & 0 \\
\hline Power press-1 (25T) & 1 & 1 & 1 & 0 \\
\hline Grinding Machine-1 & 0 & 1 & 0 & 0 \\
\hline
\end{tabular}

From the Table-IV, we plot data in Karnaugh map. Generally Karanugh map technique is used for simplifying Boolean algebra functions which are practically used in digital electronics and other electronics circuit synthesis. In Fig. 2, we simplify Karnaugh Map plot and find minimized function for noise parameters with respect to noise source.

For noise sources from different machines are represented by two attributes or variables $\mathrm{R}$ and $\mathrm{S}$, where noise from each machine is designated with the followings:

$\overline{\mathrm{R}} \overline{\mathrm{S}}$ represents average noise source from 100T Power Press machines (7 numbers).

$\overline{\mathrm{R} S}$ represents noise source from one 150T Power Press machine.

RS represents noise source from one 25T Power Press machine.

$\mathrm{R} \overline{\mathrm{S}}$ represents noise source from one Grinding Machine.

Noise parameters or variables are represented by two attributes $\mathrm{P}$ and $\mathrm{Q}$, when

$\overline{\mathrm{P}} \overline{\mathrm{Q}}$ represents $\mathrm{L}_{\mathrm{eq}}$, Noise equivalent sound level in dBA.

$\overline{P Q}$ represents $L_{a v}$, Noise average sound level in $d B A$,

$P Q$ represents $L_{A E}$, Noise sound exposure level in dBA,
$\mathrm{PQ}$ represents TWA, Noise Time Weighted Average level in dBA.

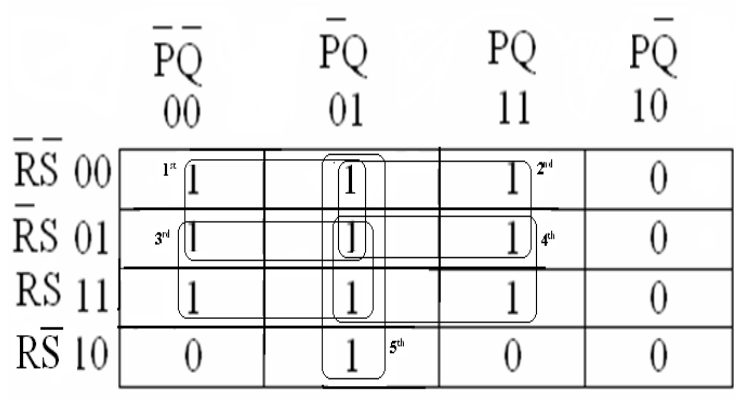

Fig. 2. Karnaugh Map plot for Noise Sources verses Noise Parameters.

We are implementing sum-of-product method used in Karnaugh map technique. Here five grouping rectangles with four number 1's in each group are possible for minimizing the sources and the parameters.

Let minimized output for the above plot is represented by $\mathrm{T}$, Then, $\mathrm{T}=\overline{\mathrm{PR}}+\overline{\mathrm{QR}}+\overline{\mathrm{PS}}+\mathrm{QS}+\overline{\mathrm{P}} \mathrm{Q}$,

Where, $\overline{\mathrm{P}} \overline{\mathrm{R}}$ indicates $\mathrm{L}_{\mathrm{eq}}$ and $\mathrm{L}_{\mathrm{av}}$ (i.e. $\overline{\mathrm{P}}$ remains in $\mathrm{L}_{\mathrm{eq}}$ and $\mathrm{L}_{\mathrm{av}}$ ) having higher than threshold value for Power press $100 \mathrm{~T}$ and $150 \mathrm{~T}$ (i.e. $\overline{\mathrm{R}}$ remains in $100 \mathrm{~T}$ and $150 \mathrm{~T}$ Power press) machines.

Similarly, $\overline{\mathrm{QR}}$ indicates $\mathrm{L}_{\mathrm{av}}$ and $\mathrm{L}_{\mathrm{AE}}$ having higher than threshold value for Power press machines 100T and 150T.

$\overline{\mathrm{PS}}$ indicates $\mathrm{L}_{\mathrm{eq}}$ and $\mathrm{L}_{\mathrm{av}}$ having higher than threshold value for Power press machines 150T and 25T.

QS indicates $\mathrm{L}_{\mathrm{av}}$ and $\mathrm{L}_{\mathrm{AE}}$ having higher than threshold value for Power press machines $150 \mathrm{~T}$ and 25T.

$\overline{\mathrm{P}} \mathrm{Q}$ indicates $\mathrm{L}_{\mathrm{av}}$ having higher than threshold value for all machines including Grinding machine.

\section{CONCLUSIONS}

Noise is one of the main resources causing environmental pollution in full order. Noise exposures from different sources (machines) of an industry or manufacturing unit are computed in this paper. By adopting Karnaugh map technique, we have minimized all the components of noise parameters or variables. Hence it ensures a holistic study of noise exposure in a real time basis. After optimizing minimized noise exposure situation, we can easily take care for safety or precautionary measure to guard against noise out-bursting as well as environmental pollution.

\section{REFERENCES}

[1] Bru“ el, Kjær, 1998a. Technical Documentation-Sound Calibrator BK4231. Bru“ el and Kjær, Naerum, Denmark.

[2] Bru“ el, Kjær, 1998b. Technical Documentation-Integrating and Logging Sound level meterBK 2238 and BK 2260. Bru“ el and Kjær, Naerum, Denmark.

[3] Griefahn B., Marks A., Robens S. “ Noise emitted road road, rail, and air traffic and their effects on sleep”, Journal of Sound and Vibration, 295(2006) 129-140.

[4] Tirtharaj Sen, Debamalya Banerjee , Bijon Sarkar "Exposure of Auto drivers to NoiseDose, in Running Condition in the Kolkata City of West Bengal State”- HWWE 2009, Calcutta University, Kolkata.

[5] Picard Michel, Girard S.A, Simard M, Larocque R. Leroux T., Turcotte F.” Accident Analysis and Prevention” J. Elsevier 40(2008), 1644-1652.

[6] T. Sen,P.K Bhattacharjee, D. Banerjee, B. Sarkar, "Running condition noise dose to auto drivers in kolkata meripolitan city of India in different seasons” International Journal of Environmental Science and Development, vol-I, no-3, pp 278-281, August 2010.

[7] Eric .D. Lynch, J. Kil,” Compounds for the prevention and treatment of noise-induced hearin loss” DDT, vol. 10, no. 19, October 2005. 
[8] S. Mum, Z.W Geem, “ Determination of individual sound power levels of noise sources using a harmony such algoroth” International Journal of Indusrial Ergonomics, vol. 39, pp. 366-370, 2009.

[9] Chucri. A. Kardous et al " Noise Dosimeter for monitoring exposure to impulse noise”, Applied Acoustics, 66(2005), 974-985.

[10] S. A Stansfeld, C. Clark, M.M Haines, "Aircraft and traffic noise exposure and children's mental health.” Journal of Environmental Psychology,vol. 29, issue 2, pp. 203-207, June 2009.

[11] ISO, International Standard: acoustics- guidelines for the measurement and assessment of exposure to noise in a working environment, ISO 9612:19997; 1997.

[12] Goelzer, B., Hansen, C.H., Sehrndt, G., 2001. Occupational Exposure to Noise: Evaluation, Prevention and Control. Publication Series from the Federal Institute for Occupational Safety and Health, Document published on behalf of the World Health Organization, (Dortmund, Berlin).

[13] T.Sen, P. K. Bhattacharjee, D. Banerjee and B. Sarkar, “ Study and Comparison of the Noise Dose on Workers in a Small Scale Industry in West Bengal, India”. International Journal of Environmental Science and Development, vol. 1, no. 4, pp. 364-367, October 2010.

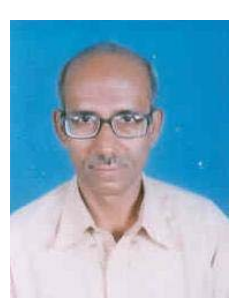

Mr. Pijush Kanti Bhattacharjee is associated with the study in Engineering, Management, Law, IndoAllopathy, Herbal, Homeopathic \& Yogic medicines. He is having qualifications ME, MBA, MDCTech, AMIE (BE or BTech), BSc(D), BIASM, CMS, PET, EDT, FWT, DATHRY, BA, LLB, KOVID, DH, ACE, FDCI etc. He had started service in Government of India, Department of Telecommunications (DoT) since 1981 as a Telecom Engineer, where he worked upto January 2007 (26 Years), lastly holding Assistant Director post at Telecom Engineering Centre, DoT, Kolkata, India. Thereafter, he worked at IMPS College of Engineering and Technology, Malda, WB, India as an Assistant Professor in the Department of Electronics and Communication Engineering from January 2007 to February 2008, from Feb 2008 to Dec 2008 at Haldia Institute of Technology, Haldia, WB, India, from Dec 2008 to June 2010 at Bengal Institute of Technology and Management, Santiniketan, WB, India and June 2010 to Aug 2010 at Camellia Institute of Technology, Kolkata, India. He joined in Assam University (A Central University), Silchar, Assam, India in Sept 2010 at the same post and department. He has written two books "Telecommunication India" \& “Computer". He is a member of IACSIT, Singapore; CSTA, USA; IAENG, Hongkong; and IE, ISTE, IAPQR, IIM, ARP, India. His research interests are in Mobile Communications, Image Processing, VLSI, Nanotechnology, Management and Environmental Pollution etc.

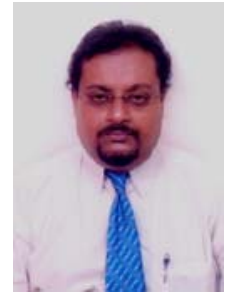

Mr. Tirtharaj Sen is an Assistant Professor in the Department of Electrical Engineering, Asansol Engineering College, Kanyapur, Vivekananda Sarani, Asansol, Burdwan-713305, India. He obtained his B.E (Electrical), M-Tech(Electrical Power) both from Calcutta University and pursuing $\mathrm{PhD}$ at Jadavpur University. He has twelve years Industrial experience in Hindustan Motors Limited(1989-2001). He was an Ex Assistant Professor \& Head, Dept. of E.E, Bengal Institute of Technology and Management, Santiniketan. (2005-2010). He has a number of publications [Both in Journals \& in Proceedings of Conferences, National \& International]. He is a member of Institution of Engineers (India) and IEEE. His research interests are in Noise Pollution, Harmonics and Non Conventional Energy.

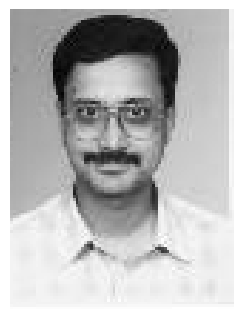

Dr. Debamalya Banerjee, Ph.D (Engg.) is currently a Reader in the Department of Production Engg. which is a centre of Advanced study in Jadavpur University, which has been rated a "Five Star University”[Highest accreditation],by NAAC[National Assessment and Accreditation Council] the official Accreditation Agency of U.G.C of Govt. of India. He has in his credit a number of publications [Both in Journals \& in Proceedings of Conferences, National \& International]. He was a visiting scientist in LfE [Lehrstuhl fur Ergonomie], TUM [Technical University of Munich], Germany and currently looks after all the Ergonomics related activities of the Department, as well as, the University. He has successfully conducted projects on Ergonomics and is currently a Life Member of Indian Society of Ergonomics (ISE), which is federated to the IEA [International Ergonomics Association].

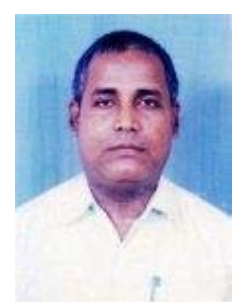

Dr. Bijon Sarkar did his Bachelor and Master of Production Engg. From Jadavpur University, Calcutta, India. Dr. Sarkar has done Doctor of Philosophy (PhD) also from Jadavpur University. He has 15 years of Experioence in the field of teaching, consultancy and research. Dr. Sarkar has published more than 114 papers in National/International conferences and Journals and got the award of Bharat Gaurav. Presently Dr. Sarkar is Professor of Production Engg. Dept. Jadavpur University, Kolkata. His field of interest includes of $\mathrm{Al}$ Techniques in Mechanical, Production Management, Tribology. He is a Life Member of Institution of Engineers(India), Indian Society of Technical Education, Society of Reliability Engineers. 